\section{A exaltação do espetáculo no Linha Direta}

\author{
Michele Negrini
}

\section{Resumo}

Na atualidade, a espetacularização é presença constante na televisão e um dos notáveis ingredientes da programação midiática. A espetacularização e a dramatização fazem parte de uma diversidade de programas que constam na grade de jornalismo das emissoras, entre eles o Linha Direta da Rede Globo. O objetivo deste artigo é refletir sobre a espetacularização midiática, com foco na observação da forma como a morte, criminosos e vítimas são apresentados no Linha Direta. Como objeto, verificamos cinco edições do programa, que foram ao ar durante os meses de outubro e novembro de 2004. Não foram levadas em consideração as edições especiais do Linha Direta Justiça. $\mathrm{O}$ artigo tem como eixo algumas idéias básicas da análise do discurso de linha francesa.

\section{Palauras-chave:}

Espetacularização, Jornalismo televisivo, Morte, Criminosos, Vítimas

\section{The exaltation of the spetacular in Linha Direta}

\section{Abstract}

Nowadays, spectacularization is always present in television as well as it is a remarkable ingredient of mediatic programmation. Spectacularization and dramatization are part of many TV programs, such as Linha Direta from Rede Globo. This article's aim is to reflect about mediatic spectacularization, focusing the observation of how death, criminals and victims are presented in Linha Direta. Our object of study are five editions of the program, which were aired during October and November 2004. The special editions Linha Direta Justiça were not taken into consideration. The article has as its axis some basic ideas of the French school discourse analysis.

Key words:

Spectacularization, Televisive journalism, Death, Criminals, Victims 
É comum ligarmos a televisão e nos depararmos com cenas onde as emoções dos envolvidos são exploradas. Recentemente, foi marcante a cobertura feita pelas principais televisões do país ao acidente com o vôo 3054 da TAM. O choro dos parentes das vítimas foi captado por todos os ângulos possíveis, enquanto repórteres questionavam estas pessoas sobre questões da vida dos que morreram. Tal cenário nos remete à visibilidade proveniente da espetacularização da informação.

A crescente presença da espetacularização nos meios de comunicação, principalmente na televisão, pode ser considerada uma tendência nos dias atuais. A apresentação de shows já é mais que um simples modismo; ela já está consolidada, e, na maioria das vezes, sustenta elevados índices de audiência. Na programação televisiva, é comum a apresentação de programas que levem ao ar debates sobre questões do cotidiano humano, como a resolução de problemas sociais de forma espetacularizada. Tais programas podem ser exemplificados pelo programa Linha Direta, da Rede Globo.

O Linha Direta é veiculado semanalmente, às quintas-feiras, geralmente apresentando $o$ relato de dois crimes ${ }^{1}$, recheados por elementos discursivos tanto do jornalismo quanto da dramaturgia. A estrutura do programa pode ser sintetizada como um ritual que se repete: apresentação do telespectador ao bom histórico da vítima e ao mau histórico do criminoso, dramatização de cenas do crime e da vida dos personagens envolvidos, depoimentos de pessoas emocionadas e de autoridades preocupadas, intercalados por aparições do apresentador, que conduz a narrativa. É comum que o apresentador remeta o telespectador à foto do criminoso, em destaque.

Quatro núcleos (Mendonça, 2001) traba- lham em conjunto na produção do programa: a coordenação de jornalismo (apuração dos fatos e redação do texto jornalístico), o núcleo de dramaturgia (direção artística), o núcleo de roteiro (texto final e organização das reportagens) e a equipe de produção.

Embora o programa faça parte da grade de jornalismo da Rede Globo, as fronteiras entre jornalismo e entretenimento são fluidas, o que dificulta sua inserção em um gênero. A simulação de diálogos entre os personagens e a encenação de fatos, somadas ao recurso da sonorização, caracterizam mais a teledramaturgia e o espetáculo que propriamente $o$ jornalismo - o que nos leva a tratar o Linha Direta como um produto híbrido.

A morte é o principal bem simbólico ofertado ao consumo do telespectador. É uma morte com autoria, reveladora do que pode haver de mais estarrecedor na espécie humana: a capacidade de matar por qualquer motivo que não seja o da sobrevivência. Este autor, comumente denominado bandido ou criminoso, é tratado pelo programa sob uma perspectiva dominante - quando não a única - que objetiva uma representação plana, uniforme, simplista e inequívoca. Já a vítima é tratada como sendo admirável, dotada de virtude e de bondade. É demonstrada como sendo uma pessoa importante no seu círculo de relações e socialmente engajada.

É sobre a espetacularização no programa Linha Direta que recai o nosso interesse nesse estudo. Vamos nos focar na reflexão sobre a forma como a morte, criminosos e vítimas são apresentados no programa. Para a análise, utilizamos conceitos básicos da análise do discurso de linha francesa. Como objeto, verificamos cinco edições do programa, as quais foram ao ar durante os meses de outubro e novembro de 2004.
${ }^{1}$ Mendonça (2001) separa os casos apresentados no programa em três tipos: casos que já foram julgados pela Justiça e cujos criminosos se encontram foragidos; casos que ainda se encontram em aberto na Justiça; casos em que não há pistas de quem realizou o crime e em que situação ocorreu.

\section{Estudos em Jornalismo e Mídia}




\section{Espetacularização no jornalismo televisivo}

A televisão, como veículo difusor de informações, que leva ao público novidades, imagens, divertimento, publicidades, é fundamental no processo de produção de sentidos e na formação do imaginário. Ela amplia a própria realidade, dando espaço para um ambiente simulado e espetacularizado.

$\mathrm{Na}$ televisão, no momento em que um fato vai ser apresentado, utiliza-se de numerosos modos de comunicação e recursos, entre os quais é pertinente ressaltar a dramatização e a espetacularização. Um dos principais motivos para se dramatizar a notícia é torná-la urgente, mesmo que no dia seguinte não seja mais lembrada e não tenha mais relevância. A tendência à dramatização é percebida não só no tratamento da notícia como na sua escolha, pois são priorizados crimes, tragédias, violência, morte, miséria (Silva, 2002).

Através da dramatização há a possibilidade de criação de uma relação de encantamento com o telespectador (Rosário, 2001). A dramatização reforça o realismo dos fatos apresentados e faz com que as pessoas que estão frente à tela tenham a confirmação da veracidade do conteúdo da informação.

Uma forte estratégia de sedução utilizada pelos textos televisivos é a simulação, consubstanciada não como representação, mas como simulacro, como aparência sem realidade. Essa estratégia encanta e presenteia o espectador com o sonho e com a fantasia. A simulação permite tudo, ou quase tudo. Através da violação da fronteira da realidade é possível mais do que representar, do que "fazerde-conta”, é possível quase vivenciar aquilo que não tem existência e, dessa maneira, estimular o espectador a recorrer à sua capacidade de fantasiar, de preencher vazios de sentidos com prazeres; de preencher os tristes vazios do mundo com sonhos encantados (Rosário, 2001: 85).

A simulação cria a ilusão de que o fato está acontecendo ao vivo, no momento e que os detalhes picantes são verdadeiros. Com a utilização da imagem e dos sons integrados com a palavra, a televisão oferece ao receptor a legitimação do que está sendo transmitido. As pessoas conseguem facilmente identificar personagens conhecidos na televisão e informações vistas neste meio. A imagem, elemento diferencial da simulação televisiva, é essencial no processo de espetacularização dos produtos midiáticos. Squirra (1993) relaciona a televisão com a espetacularização: "Desde o seu advento, a televisão tem sido o veículo preferido na disseminação de informações e peça fundamental para o entretenimento das sociedades" (Squirra, 1993: 9). Fischer concorda:

Na TV, o público encontra todo tipo de shows: desde aqueles que, através de reportagens, mostram o lado espetacular da vida, o sensacionalismo, os fatos insólitos, até os musicais e os programas de competições com a participação de auditório. Enquanto nas novelas, filmes e desenhos animados, os espectadores assistem à narração de uma história, nos sho$w s$ recebem a sucessão de imagens e sons em forma de mosaico. (Fischer, 1984: 65)

O formato espetacular pode ser considerado uma fórmula capaz de atrair os mais diversificados públicos. Devido à dimensão adquirida pelos programas espetacularizados no contexto social, a inserção destes programas principais motivos

para se dramatizar a notícia é torná-la urgente, mesmo que no dia seguinte não seja mais lembrada e não tenha mais relevância 
na grade das emissoras já é um item obrigatório (Bucci, 1993). Na concorrência por audiência, o espetáculo não pode ficar de fora:

Aos poucos, a televisão permitiu que o universo policial se incorporasse ao seu dia-a-dia. Não tinha escolha. No negócio do entretenimento, ao menos no Brasil, a espetacularização do mundo-cão deixou de ser um item opcional para ser obrigatório. Assim, o tabu do mundo-cão dentro do vídeo - que já havia sido subvertido com tentativas isoladas - foi quebrado no final da década de 80. (Bucci, 1993: 101-102).

Embora concordemos com a idéia de que a televisão tem poderes sobre o telespectador, neste trabalho nos filiamos a Wolton, que diz que a televisão pode influenciar o público, mas não o manipula. "[...] o público nunca é passivo ou alienado. Ele pode ser influenciado, principalmente por programas de baixa qualidade, mas falar em alienação suporia a perda do seu livre-arbítrio" (Wolton, 2003: 67).

Pertencemos a uma cultura que identifica o ver com o conhecimento, e o desenvolvimento tecnológico dos meios tem reforçado a importância da percepção visual. Desta forma, com a supremacia visual, a espetacularização da informação em meios como a televisão tem tido considerável propagação. Cada vez mais, presenciamos programas apelativos, sensacionais e espetacularizados na programação diária dos meios de comunicação.

Com a crescente disseminação do sensacional e com a tendência de tornar as peculiaridades da vida humana privada relevantes ao conhecimento social, os shows espeta-

\section{Pertencemos a uma cultura que identifica o ver com o conhecimento, e o desenvolvimento tecnológico dos meios tem reforçado a importância da percepção visual}

culares têm espaço cada vez mais garantido em vários setores da sociedade, como nos meios de comunicação, na literatura, nas galerias de arte, em igrejas e na vida humana como um todo. O cotidiano humano está rodeado de uma imensa teatralização.

O telejornal, mais que o jornalismo impresso, tem de entreter. O tempo todo. Uma nota entediante de 10 segundos é fatal. O telespectador foge. A cor é obrigatória. O movimento é obrigatório. O retumbante é obrigatório. É por isso que o principal critério da notícia é a imagem. Se não há uma imagem impactante, dificilmente o fato merecerá um bom tempo no telejornal. O apresentador do telejornal é outro ingrediente-chave. Ele desenvolve com o telespectador um vínculo de familiaridade como se fosse um ator, um astro. Vivemos em um tempo que jornalistas da TV são celebridades, são símbolos sexuais. Enfim, aqui, como no resto do mundo, o público sente desejo pelo programa do telejornal (Bucci, 2000: 29).

Um campo onde a espetacularização tem ganhado espaço nos últimos anos é o jornalismo. Programas jornalísticos estão adotando a apresentação de variedades como integrantes de sua linha editorial e utilizando-se do recurso da encenação. A apresentação de quadros de dramaturgia, nos quais se explora desde as mais cômicas às mais perversas atitudes humanas, é vista comumente em programas jornalísticos.

A presença da espetacularização no campo jornalístico e a apresentação de notícias shows são conseqüências do domínio da observação sobre a explicação. A apresentação do chocante, do insólito e do sensacional prende o público. Para um noticiário ter boa audiência, é imprescindível que o espetáculo 
2 O francês Guy Debord, autor da obra A Sociedade do Espetáculo, é um pensador marxista que acredita que o espetáculo tem poderes de alienação e dominação sobre a sociedade e que a sociedade do espetáculo é aquela em que as ilusões substituirram o natural, o espontâneo e o autêntico da vida humana. Das idéias de Marx, Debord destaca o fetichismo da mercadoria e a alienação. Debord era filósofo, diretor de cinema e escritor; era influenciado pelo Dadaísmo e pelo Surrealismo.

Definia-se como um doutor no nada e agitador social. Era um humanista, que tinha preocupações com o cotidiano das cidades e sua provável desestruturação, provocada pelo mundo das imagens. $O$ autor preocupa-se com a idéia da tirania das imagens e da submissão alienante da sociedade aos impérios da mídia. seja completo, que a realidade oferecida seja total, global e natural. O impacto de uma notícia acontece com a exposição de uma imagem mais forte, mais espetacularizada que aquelas que o espectador pode observar no seu convívio (Canavilhas, 2004).

Um conhecido estudioso da presença da espetacularização na sociedade é o francês Guy Debord. Na opinião de Freire Filho (2003), o espetáculo tratado por Debord ${ }^{2}$ (1997) deve ser entendido como um desdobramento da abstração generalizada ligado ao funcionamento do capitalismo. Assim, para Debord, o capital chegou a um grau de acumulação que se tornou imagem:

A primeira fase da dominação da economia sobre a vida social acarretou, no modo de definir toda a realização humana, uma evidente degradação do ser para o ter. A fase atual, em que a vida social está totalmente tomada pelos resultados acumulados da economia, leva a um deslizamento generalizado do ter para o parecer, do qual todo "ter" efetivo deve extrair seu prestígio imediato e sua função última. Ao mesmo tempo, toda realidade individual tornou-se social, diretamente dependente da força social, moldada por ela (Debord, 1997: 18).

O conceito de espetáculo está intimamente relacionado com a vida humana, ele é a sua afirmação como aparência:

O conceito de espetáculo unifica e explica uma grande diversidade de fenômenos aparentes. Sua diversidade e contraste são as aparências dessa aparência organizada socialmente, que deve ser reconhecida em sua vertente geral. Considerado de acordo com seus próprios termos, o espetáculo é a afirmação da aparência e a afirmação de toda a vida humana - isto é, social - como simples aparência (DEBORD, 1997: 16).

Debord, já na primeira tese da obra $A$ sociedade do espetáculo, mostra que na sua concepção o espetáculo está presente em toda a sociedade: "Toda a vida das sociedades nas quais reinam as modernas condições de produção se apresenta como uma imensa acumulação de espetáculos. Tudo o que era vivido diretamente tornou-se representação" (Debord, 1997: 13).

\section{Análise do discurso}

A Análise do Discurso (AD) de perspectiva francesa, que surge especialmente a partir das sistematizações de Michel Pêcheux sobre conceitos fundadores de Mikhail Bakhtin e Michel Foucault, é uma linha de investigação que tem por objeto textos, que são ao mesmo tempo lingüísticos e históricos. O discurso articula a língua com a história, sendo ele mesmo um "efeito de sentidos" - que existiam antes dele e que vêm conformá-lo naquele contexto específico, enunciado por aqueles atores determinados, naquele momento histórico.

O texto como objeto de pesquisa implica que se tome a Análise do Discurso como um quadro de referência conceitualmente organizado, mas metodologicamente aberto. É preciso ouvir com atenção o que dizem - e como dizem - os textos que o analista tomou como objeto. A AD tem uma preocupação que ultrapassa a hermenêutica. É preciso ir além da interpretação dos sentidos de um texto: é preciso entender como o discurso funciona. Que lógica o movimenta, que elementos são repetidos, que elementos são silenciados; onde este discurso tem lugar, que posições de sujeito são ocupadas, como os atores se 
movimentam nessas posições ideologicamente definidas; quem fala, que espaços ocupa.

Sabemos que não há discurso sem sujeito e que não há sujeito sem ideologia (Orlandi, 2001). A relação entre linguagem, mundo e pensamento torna-se possível porque a ideologia intervém com o seu modo de funcionamento imaginário, e o indivíduo, interpelado pela ideologia, torna-se sujeito de um dizer. Orlandi salienta que, pela interpelação ideológica que transforma o indivíduo em sujeito, inaugura-se a discursividade: a posição de sujeito é um lugar que o indivíduo momentaneamente ocupa para ser sujeito do que diz. Esse "lugar" é definido por elementos que vão além das singularidades do indivíduo que fala. Ao falar, o indivíduo se movimenta ao longo de uma série de posições de sujeito - e, sempre que muda de uma para outra, incorpora uma perspectiva a partir da qual deve falar.

Os sentidos de um texto variam conforme as estratégias postas em funcionamento na construção do discurso, a constituição dos sujeitos que falam e dos sujeitos que lêem ${ }^{3}$, o meio em que este texto se materializa lingüisticamente, as relações de poder aí conformadas. As formações discursivas, estas regiões de sentido que se definem nas suas relações com outras formações discursivas, são reflexos das relações entre sujeito e ideologia, e, quando localizadas, permitem ao analista estabelecer regularidades no funcionamento do discurso. A construção dos sentidos, portanto, está intimamente relacionada aos interlocutores do discurso, ao que fala e ao que lê.

A linguagem é tratada por Bakhtin como inerentemente dialógica. A figura do outro é imprescindível na construção do discurso, pois não se pode pensar o homem fora de suas relações. "Toda palavra serve de expressão a um em relação ao outro. Através da palavra, defino-me em relação ao outro, isto é, em última análise, em relação à coletividade. A palavra é uma espécie de ponte lançada entre mim e os outros" (Bakhtin, 1986: 113).

O diálogo é a condição da linguagem e do discurso, mas existem textos monofônicos e polifônicos, de acordo com as estratégias discursivas empregadas.

Nos textos polifônicos, os diálogos entre discursos mostram-se, deixam-se ver ou entrever; nos textos monofônicos eles se ocultam sob a aparência de um discurso único, de uma única voz. Monofonia e polifonia são, portanto, efeitos de sentido, decorrentes de procedimentos discursivos, de discursos por definição e constituição dialógicos. Nos textos polifônicos escutam-se várias vozes, nos monofônicos uma apenas, pois as demais são abafadas (Barros, 1999: 36).

Ducrot (1987) contesta o pressuposto da unicidade do sujeito falante, mesmo que algumas pesquisas considerem como óbvio que cada enunciado possui somente um autor. Ele lembra que a crença da unicidade do sujeito falante esteve presente durante muito tempo e não foi questionada até que Bakhtin elaborou o conceito de polifonia.

Para Bakhtin, há toda uma categoria de textos, e notadamente de textos literários, para os quais é necessário reconhecer que várias vozes falam simultaneamente, sem que dentre elas seja preponderante e julgue as outras: tratase do que ele chama, em oposição à literatura clássica ou dogmática, a literatura popular, ou ainda carnavalesca, e que às vezes ele qualifica de mascarada, entendendo por isso que o autor assume uma série de máscaras diferentes. Mas esta teoria de Bakhtin, segundo meu
${ }^{3}$ Considerando-se todo receptor, independentemente do veículo, como "leitor", e a leitura como um ato de produção de sentidos.

\section{Estudos em Jornalismo e Mídia}


4 "Geralmente entende-se por vítima toda pessoa que é sacrificada em seus interesses, que sofre um dano ou é atingida por qualquer mal. E, sem fugir ao sentido comum, na linguagem penal designa o sujeito passivo de um delito ou de uma contravenção. É, assim, o ofendido, o ferido, o assassinado, o prejudicado, o burlado"(SILVA, 1998: 503). conhecimento, sempre foi aplicada a textos, ou seja, a seqüências de enunciados, jamais aos enunciados de que estes textos são constituídos. De modo que ela não chegou a colocar em dúvida o postulado segundo o qual um enunciado isolado faz ouvir uma única voz (Ducrot, 1987: 161).

Há um entrecruzamento de vozes em um mesmo texto, e um enunciado assimila, em sua enunciação, a superposição de diversas vozes.

Ducrot utiliza-se da noção de polifonia de Bakhtin para diferenciar um sujeito enunciador de um locutor. Para ele (1987: 182), o locutor é "um ser que é, no próprio sentido do enunciado, apresentado como seu responsável". O enunciador é a figura responsável pela produção de sentidos no enunciado, que mostra o ponto de vista de onde se posiciona o locutor.

O locutor, responsável pelo enunciado, dá existência, através deste, a enunciadores cujos pontos de vista e cujas atitudes ele organiza e assimila. "Direi que o enunciador está para o locutor assim como a personagem está para o autor" (Ducrot, 1987: 192). O locutor pode ser comparado a um narrador, que é dado como a fonte de um discurso. Mas as atitudes expressas no discurso são atribuídas a enunciadores, que mostram seus pontos de vista no texto. Isso quer dizer que locutores diferentes podem ser veículos de um mesmo enunciador - é exatamente o que observaremos em nossa análise.

No discurso do programa Linha Direta, evidenciamos quatro pontos de vista principais: a perspectiva da emissora - evidenciada nas falas do apresentador do programa e do narrado (E1); a perspectiva favorável à vítima - por meio das pessoas ligadas à vítima (E2); a perspectiva favorável ao cri- minoso - evidente nas falas de pessoas ligadas ao criminoso ou do próprio criminoso (E3); perspectiva legal ou testemunhal - por meio das falas de pessoas ligadas à Justiça ou testemunhas do crime (E4).

Para a realização da análise do Linha Dire$t a$, foram tomadas como corpus cinco edições do programa, levadas ao ar durante os meses de outubro e novembro de 2004. Fazem parte da amostra todas as nove histórias integrantes dos cinco programas exibidos nestes dois meses. Foram excluídas do corpus de análise as edições especiais do Linha Direta Justiça.

Tratando-se de vítimas ${ }^{4}$, a sua caracterização no Linha Direta segue uma forma simplista e sem um trabalho mais apurado de problematização: elas são retratadas como pessoas admiráveis, dotadas de virtudes e bondade. São indivíduos tidos como importantes no círculo de suas relações e socialmente engajados - a morte, carregada de violência, representa não apenas uma perda familiar, mas também para a sociedade.

Para a análise da imagem da vítima, localizamos as Formações Discursivas principais e os sentidos que lhe são associados, inserindo a problemática das perspectivas de enunciação. As FDs próprias desse discurso narram uma vítima: a) com a família estruturada; b) batalhadora; c) de bom caráter.

\section{a) com família estruturada}

Fevereiro deste ano. Clóvis [vítima] liga para a mãe e avisa que vai passar o final de semana em Recife. A mãe comenta a briga entre os dois filhos. Eurico ouve a conversa em uma extensão e se irrita. (E1).

Aí ela [vítima Márcia] pegou e falou que não tinha nada [não tinha nada para dar aos bandidos 
que a mataram]. O que ele quisesse levar, ele podia levar, porque ali ela não tinha nada. Que ela tinha de mais importante era os filhos dela. Aí, ele falou que dali ele não queria nada, que só estava ali para matar ela. (E2).

b) batalhadora

Apesar da surra, Rita [vítima] volta ao trabalho. Enquanto isso, Buguelo [assassino] segue para casa. (E1).

Que que essa mulher [referindo-se a assassina] aprontou na vida dela. Fazer tanta coisa de mal pra uma pessoa que não merecia, né. Uma pessoa trabalhadora, caprichoso, que se dedicava à família, mulher e aos filhos. (E2).

Ele [criminoso] atravessou a estrada com uma arma na mão. E queria acertar umas contas com Ildelmar. E eu não sabia do que estava se passando. Então eu falei: não, você não vai matar o homem aqui na minha frente porque o Ildelmar é uma pessoa trabalhadora, não faz maldade a ninguém, ele é uma pessoa que a gente conhece já há mais de quinze anos. (E4).

c) de bom caráter

Um dia, José Reis [vítima] chega a oferece um pedaço de terra para Helton [seu assassino] criar animais. (E1).

E o Ildelmar [vítima] correu por cima dele [criminoso] pra ele não fazer isso [Ildemar quis impedir que Billy Kid acabasse com uma festinha de crianças]. Não faz isso, você está louco. É uma festa de criança, e tal. (E2).

\section{A descrição dos criminosos no Linha Direta está associada a uma visão plana - e sem qualquer complexidade ou problematização \\ - de um indivíduo completa e essencialmente mau}

A pessoa que pegou ela [vítima] tinha que ser conhecido. Ela não saia com estranho, jamais. (E2).

Waldecir [vítima] queria vender a casa para dividir o valor desse dinheiro e cada um seguir o seu caminho [a vítima queria dividir o dinheiro com a ex-mulher]. Mas, Francisca [assassina], que já estava residindo na casa com seu novo companheiro, não estava concordando com aquela situação de venda da casa. (E4).

A descrição dos criminosos no Linha Direta está associada a uma visão plana - e sem qualquer complexidade ou problematização - de um indivíduo completa e essencialmente mau. As falas da maior parte dos locutores condenam os criminosos a partir da narração sobre suas características inequivocamente perversas, contribuindo para reforçar uma lógica maniqueísta. Analisando o objeto de estudo, identificamos as Formações Discursivas que estabelecem os sentidos sobre o criminoso do Linha Direta. Após a identificação dessas FDs, foi interposta à análise a problemática do enunciador, para compreender de que ponto de vista esses sentidos são construídos. São os resultados dessa análise que trazemos a partir de agora, em três Formações Discursivas principais sobre o criminoso: a) desequilibrado e dependente químico; b) com dificuldades nos relacionamentos; c) agressivo e perigoso.

\section{a) desequilibrado e dependente} químico

Depois de se despedir do cunhado de Rita [vítima], Buguelo [assassino] voltou para casa. Foi quando ele cometeu a primeira 
loucura. (E1). Depois de recusar o almoço, Buguelo [criminoso] compra uma garrafa de cachaça. (E1).

E toda a vez que ele [criminoso] dava uma bicada, ele dava uma 'puxada' na maconha. Chegava com a folha da maconha e batia dentro do copo. "Meu irmão não adianta você fazer isso, não, que você vai se prejudicar. Você vai ficar muito louco". Aí ele falou que: é pra isso que eu quero mesmo. É ficar muito louco. (E2).

Ele [criminoso] era usuário de drogas: maconha e também consumia bebida alcoólica em larga escala. Então, ele era pautado pela violência, por parte dele em relação a ela [vítima]. (E4).

\section{b) com dificuldades nos relacionamentos}

No início, o casamento de Francisca [assassina] e Waldecir [vítima] dá certo, mas Francisca se revela muito ciumenta. Para não brigar, ele aceita as imposições da mulher. (E1).

Aí ela [assassina] levou a filha dela para uma outra escola, porque ela achou que ele [vítima] estava querendo a filha dela. (E2).

Eles [assassino e vítima] brigavam muito. [Inaudível] Porque o outro [vítima] tinha mais acesso. Tinha brinquedo melhor. (E4).

Ele [assassino] ficou com ciúmes de alguma coisa e passou a se descontrolar, uma confusão em cima de confusão (E4).

c) agressivo e perigoso
Festa em frente da casa de Billy Kid. Mais uma vez ele reclama do barulho e ele saca a arma. Há uma troca de tiros. Os moradores reagem e invadem a casa de Billy Kid. Eles exigem que o pedreiro vá embora. (E1).

Billy Kid aproveita que Ildelmar tinha bebido para agredi-lo. Ele vai para casa com hematomas e ferimentos por todo o corpo (E1).

E ele [o assassino Eurico] faz ameaças por telefone, dizendo que ele iria resolver da maneira dele com ele [a vítima Clóvis], que ele iria pagar a ele. (E2).

Ele [assassino] abre a boca dela [mãe] e tirou o bilhete. Era para um namorado. Aí foi mais de uma briga deles dois. Porque Clóvis não aceitava, ele vivia brigando com a mãe. (E4).

Foi uma pessoa que não mostra qualquer arrependimento dos crimes que pratica e realmente é uma pessoa que é um perigo para a sociedade (E4).

A morte apresentada no Linha Direta pode ser analisada de acordo com a Formação Discursiva que trata de uma morte direcionada. Na maior parte dos casos do programa, o assassino tem o foco específico em alguém de suas relações, seja familiar, amorosa ou profissional. Os sentidos principais que demarcam a morte no programa podem ser evidenciados através de características como a) morte violenta; b) morte motivada por vingança e inveja. Essas características vão ao encontro da idéia de um homicídio praticado para que o criminoso possa acabar com quem esteja perturbando os seus planos. 


\section{a) Morte violenta}

Em seguida Eurico [o assassino] atira na cunhada [vítima]. Trancada no quarto com o menino, a criada ouve tiros. Eurico descarrega a arma no irmão [vítima] e na cunhada [vítima]. Depois de matar o irmão e a cunhada, Eurico encontra uma tia na rua. Ele diz apenas uma frase: fiz uma desgraça e foge. Quarenta minutos depois a babá sai do quarto com o filho dos patrões no colo (E1).

O cunhado de Buguelo [assassino] sai de casa. Buguelo diz a ele que não vai fazer nada com a mulher. O pai de Rita, que tem problemas de locomoção, tenta ajudar. O pai de Rita cai no chão. Rita implora para não morrer. Mas Buguelo não tem pena da mãe de seus três filhos [ele assassina a mulher com várias facadas]. (E2).

O da pracinha fui eu, eu. O Carlão falou pra mim: Esse cara tava na parada. Aí, eu sai estalando ele, ele caiu, eu estalando, estalando, estalando e parei com a pistola aberta. (E3).

Agressões, bofetadas e também por um tipo de [Inaudível]. Ela [vítima] foi morta por asfixia. (E4).

\section{b) Motivada por vingança e inveja}

Como o portão da frente está fechado, Eurico [assassino] entra por um buraco na parede dos fundos. Ele quebra o portão feito para segurança do bebê [filho da vítima] e invade o apartamento. Para Eurico, é o dia do acerto de contas com o irmão. (E1).

É uma coisa [a morte] que eu acho que se passa

não só pela questão financeira, pela questão de partilha, mas com certeza, se passou por aí a inveja. Vê o irmão [vítima Clóvis] bem, vê o irmão feliz, vê o irmão bem casado, vê o irmão com a família que ele não tinha, tanto é que ele [assassino Eurico] matou a Lúcia para tirar a felicidade dele. (E3).

Se reuniram [policiais participantes de Vigário Geral] e planejaram uma revolta, uma represália. Matar os traficantes que mataram o seu líder, o sargento Ailton, e mais quatro companheiros de criminalidade [os policiais queriam vingar a morte dos colegas]. (E4).

\section{Considerações finais}

O Linha Direta é um espetáculo que salienta os atos bárbaros do cotidiano humano. Antes de chegar à morte, a violência é espetacularizada de forma a "tentar evidenciar" a crueldade do assassino. O programa utilizase dos recursos da emissora para construir cenas cujos rituais de violência são levados ao gosto do público com a explicitação de mínimos detalhes. São em situações como estas que salientamos a amplitude do discurso do Linha Direta, apesar de não nos termos detido em discutir a violência neste trabalho.

O discurso do Linha Direta é notadamente polifônico, apresentando uma grande diversidade de vozes. A problematização que propomos vai além do mapeamento dessa evidência: nossa pergunta é se diversidade significa, por fim, pluralidade. Os casos narrados no programa, como os que analisamos aqui, apresentam uma série de depoimentos. Porém, temos muitos locutores falando basicamente sob uma perspectiva, um ponto de vista - seguindo a definição de Ducrot, muitos locutores e um único enunciador. Como o enunciador é "a pessoa 
de cujo ponto de vista são apresentados os acontecimentos" (Ducrot, 1987: 195), é essa perspectiva que dá forma aos sentidos.

Se quisermos realmente compreender como determinados sentidos estão sendo reiterados, não podemos parar na identificação dos locutores, mas devemos avançar rumo aos enunciadores. São eles que indicam as posições de sujeito ocupadas pelos indivíduos que falam, são eles que vêm configurados ideologicamente, são eles os personagens incorporados por atores diversos. O enunciador é a perspectiva da qual o locutor enuncia. É essa perspectiva que articula as formações discursivas - que definem, na acepção clássica de Pêcheux, o que pode e deve ser dito daquela posição determinada.

Se ficarmos com a perspectiva de um único enunciador, vamos nos deparar com um discurso plano. No caso do Linha Direta, temos um discurso maniqueísta, que mostra criminoso como tendo somente defeitos, a vítima portadora de somente qualidades e a morte como sendo "algo" sem complexidades para as pessoas, tratado sempre de forma similar. Desta forma, podemos dizer que o programa está muito longe de tratar os crimes com objetividade e de levar em consideração a velha idéia de imparcialidade jornalística. A opinião do programa sobre os crimes e seus objetivos se torna nítida a quem observar o seu discurso mais minuciosamente.

Se pensarmos na posição enunciativa das pessoas ligadas à vítima, que são tratadas neste estudo como E2, é de se esperar que elas condenem o criminoso de forma inequívoca. O mesmo tipo de descrição, porém, não é inerente à posição enunciativa da emissora (E1), que, por ocupar um lugar de fala jornalístico, estaria - ao menos por definição
- preocupada em narrar os fatos e contemplar a complexidade dos personagens. Nesta análise, porém, constatamos que E1 constrói os mesmos sentidos de E2, aliando-se à perspectiva de enunciação da vítima e evitando qualquer tipo de polêmica.

Estamos diante de um programa que toma para si os papéis da polícia e da Justiça e que tem como um dos fatores de seu sucesso estar ancorado em uma emissora de retrospecto como a Globo. A emissora utiliza-se de sua credibilidade para disputar autoridade com a polícia e com a Justiça. O programa pode parecer um justiceiro, se o pensarmos de uma maneira geral, mas no momento em que é observada a sua estrutura narrativa e os depoimentos, a idéia de que o Linha Direta pensa somente no bem da população e em tirar criminosos da rua é desbancada. É perceptível que estamos diante de uma busca por audiência. Programas como o Linha Direta, híbrido de jornalismo e espetáculo fundados na violência, mobilizam preocupações ao mesmo tempo sociais e atávicas.

A complexidade intrínseca ao caos é soterrada por meio de um discurso que opta por estratégias de simplificação e redução. Não retrata seres humanos que se movem entre tensões e contradições, e sim pessoas que são "ou isto ou aquilo". É uma fórmula espetacular, de fácil entendimento e que ajuda a manter a visão de que o mundo se divide entre os totalmente maus e os totalmente bons, estando estes à mercê da crueldade daqueles.

\section{Sobre a autora}

Michele Negrini, Doutoranda em Comunicação da PUC-RS, docente da UFSM/ Unipampa São Borja.

Email:mmnegrini@yahoo.com.br 


\section{Referências}

BAKHTIN, Mikhail. Marxismo e filosofia da linguagem. 3.ed. São Paulo: Hucitec, 1996.

BARROS, Diana Luz Pessoa. Contribuições de Bakhtin às teorias do texto e do discurso. In: FARACO, Carlos Alberto (org). Diálogos com Bakhtin. 2 ed. Curitiba: UFPR, 1999.

BUCCI, Eugênio. O peixe morre pela boca. São Paulo: Scritta, 1993.

BUCCI, Eugênio. Brasil em tempo de TV. 3 ed. São Paulo: Boitempo, 2000.

DEBORD, GUY. A Sociedade do Espetáculo. Rio de Janeiro: Contraponto, 1997.

DUCROT, Oswald. O dizer e o dito. Campinas: Pontes, 1987.

FISCHER, Rosa Maria Bueno. O mito na sala de jantar: discurso infanto-juvenil sobre a televisão. Porto Alegre: Movimento, 1984.

FREIRE FILHO, João. A sociedade do espetáculo revisitada. Revista Famecos. Porto Alegre. N. 22, dezembro de 2003.

MENDONÇA, Kleber. Estratégias de autoridade em tempos de participação interativa: uma análise do programa "Linha Direta". In: $10^{\circ}$ Encontro Anual dos Programas de Pós-Graduação em Comunicação, 2001, Brasília. Anais. Brasília: Compós, 2001.

ORLANDI, Eni. Análise do discurso: princípios e procedimentos. 3 ed. Campinas: Pontes, 2001.

PINTO, Ivonete. A dramatização no telejornalismo: Caras e bocas fazendo a notícia. Dissertação de mestrado defendida no Programa de Pós-Graduação em Comunicação da PUC-RS, 1998.

ROSÁRIO, Nísia Martins do. Televisão: simulação em tempo real e sedução em tempo integral. Verso e Reverso. Ano XV. No 32. 2001. São Leopoldo: Unisinos.

SILVA, Oscar José de Plácido e. Vocabulário Jurídico. $15^{\text {a }}$ ed. Rio de Janeiro: Forense, 1998.
SQUIRRA, S. Leituras de imagens. In: LOPES, Dirceu Fernandes; TRIVINHO, Eugênio (orgs.). Sociedade midiática: significação, mediações e exclusão. Santos: E. Universitária Leopoldianum, 2000.

WOLTON, Dominique. Internet, e depois? Uma teoria crítica das novas mídias. Porto Alegre: Sulina, 2003.

\section{Referências Webgráficas}

CANAVILHAS, João. O domínio da informaçãoespetáculo na televisão. Disponível em: www. bocc.ubi.pt. Acesso em: 7 de março de 2004. SILVA, Giane David da. A informação televisiva entre a realidade e a ficção. Disponível em: http:// www.ufop.br/ichs/conifes/anais/LCA/clca01.htm. Acesso em: 5 de dezembro de 2002.

Recebido em 3 de março de 2008 Aprovado em 28 de abril de 2008

\section{Estudos em Jornalismo e Mídia}

Ano V № 1 - 1 semestre de 2008 